\title{
Prediction of Perinatal Outcome with Meconium-stained Liquor
}

\author{
Monowara Khatun, ${ }^{1}$ Runa Parvin, ${ }^{2}$ Samaria Naurin ${ }^{3}$
}

\begin{abstract}
Background \& objective: Passage of meconium in the amniotic fluid during labor has long been considered as fetal compromise resulting from fetal hypoxia or increased vagal activity from cord compression. It is also a sign of normal gastrointestinal tract maturation under neuronal control. However, presence of meconium in the amniotic fluid is traditionally viewed as unfavorable perinatal outcome. So, the present study was contemplated to find the association between grade of meconium during labor and perinatal outcome.

Methods: The present prospective study was conducted in the North Bengal Medical College, Sirajganj between January 2016 - April 2017. Based on predefined criteria, 53 singleton pregnant women with meconium-stained liquor (MSL) on spontaneous or artificial rupture of membrane after 37 completed weeks of gestation were included in the study. Meconium-stained liquor was graded as "Thick" if the fluid was dark green in colour, viscous, tenacious, opalescent or opaque containing large amount of particulate materials and "Thin" if the fluid was translucent, light yellow green in colour without particulate material. The perinatal outcome was evaluated in terms of APGAR score of neonates at 1 and at 5 minutes of birth, NICU admission, resuscitation needed, jaundice and respiratory distress syndrome (RDS) due to meconium aspiration. Asphyxia neonatorum was diagnosed if APGAR at birth and/or at 5 minutes was $<7$. All the outcomes were then compared between mothers forming 'Thick' and 'Thin' meconium cohort.
\end{abstract}

Result: Of the 53 meconium-stained liquor, nearly half (49\%) was with 'Thick' meconium and the half (51\%) was with 'Thin' meconium. Approximately $85 \%$ of the neonates were delivered by lower uterine caesarean section (LUCS) and $80 \%$ of the neonates were asphyxiated at birth which reduced to $15.1 \%$ at 5 minutes. More than three-quarters $(75.5 \%)$ of the neonates required resuscitation and $28.3 \%$ had respiratory distress syndrome (RDS). The incidences of asphyxia neonatorum, resuscitation needed and RDS were significantly higher in 'Thick' meconium cohort than those in 'Thin' meconium cohort with risks of having these conditions in the former cohort being $6(95 \% \mathrm{CI}=1.1-31.2), 4.5(95 \% \mathrm{CI}=1.1-18.9)$ and $4.2(95 \% \mathrm{CI}=1.1-15.7)$ times higher respectively than those in the latter cohort $(p=0.021, p=0.031$ and $p=0.026$ respectively).

Conclusion: Majority of the neonates born of mothers with thick meconium cohort are asphyxiated, need resuscitation and/or develop RDS. Asphyxia neonatorum, need for resuscitation and RDS are significantly higher in 'Thick' meconium cohort than those in 'Thin' meconium cohort with risks of having these conditions in the former cohort being several times higher than those in the latter cohort.

Key words: Prediction, perinatal outcome, meconium-stained liquor etc.

\section{INTRODUCTION:}

Fetal well-being has traditionally been evaluated on the basis of fetal activity, fetal heart rate (FHR) and presence of meconium in amniotic fluid in vertex presentation. Presence of meconium in the amniotic fluid is considered as a physiological sign of fetal maturity, on one hand and as an ominous sign for fetal distress on the other hand. ${ }^{1}$ Fetal distress is defined as alterations in the fetal heart rate (FHR) more commonly bradycardia and the passage of meconium in response to hypoxic

\section{Authors' information:}

Dr. Monowara Khatun, Associate Professor (Obstetrics \& Gynaecology), Thangamara Medical College \& Rafatullah Community Hospital, Bogura.

2 Dr. Runa Parvin, Assistant Professor (Obstetrics \& Gynaecology), Shaheed Ziaur Rahman Medical College, Bogura.

${ }^{3}$ Dr. Samaria Naurin, Registrar (Obstetrics \& Gynaecology), Thangamara Medical College \& Rafatullah Community Hospital, Bogura. Correspondence: Dr. Monowara Khatun, Cell Phone:01712681791,E-mail:monowara.m19@ gmail.com. 
insult. Variations in FHR, passage of the meconium in the amniotic fluid, pathological or abnormal CTG and decreased fetal scalp blood pH are strong indicators of fetal distress. ${ }^{2}$

Aspiration of meconium by the fetus is a common cause of perinatal morbidity and mortality, for it is difficult to prevent. The fetus passes meconium into the amniotic fluid in $10 \%$ of all pregnancies; in $5 \%$ of these (1:200 of all pregnancies) the meconium is aspirated into the lungs of the fetuses or the neonates. This can result in severe respiratory distress, called meconium aspiration syndrome (presence of meconium below the vocal cord). ${ }^{3}$ Meconium reduces the antibacterial property of amniotic fluid by altering the level of zinc in it which leads to intra-amniotic infections. In case of hypoxia, gasping of fetus results in meconium aspiration which neutralizes the surfactant action and promotes inflammation of lung tissues, whereas persistent hypoxia after birth, aspirated meconium results in pulmonary vascular and pulmonary hypertension. ${ }^{4}$

Conflicting outcomes have been reported in the labors, complicated by meconium staining of the amniotic fluid, varying with the degree of meconium staining..$^{5-7}$ Meconium staining amniotic fluid (MSAF) is associated with higher rate of caesarean delivery, increased need for neonatal resuscitation and meconium aspiration syndrome. $^{8}$ As per previous studies, $5 \%$ of neonates born through meconium stained amniotic fluid develop MAS (meconium aspiration syndrome). ${ }^{9}$ The MAS can cause or contribute to neonatal death and, in addition, up to one-third of cases may develop long-term respiratory compromise. ${ }^{10}$

In contrast many studies, however suggest that MSAF is a low-risk obstetrical hazard because the perinatal mortality rate attributable to meconium is only 1 death per 1000 live-birth. Many researchers have, therefore, disregarded the significance of MSAF as an indicator of fetal distress. ${ }^{1,11}$ Although the direct and indirect effects of meconium staining are not clearly known, MSAF is considered as a predictor of maternal and perinatal morbidity and mortality. The present study was carried out to find the maternal and perinatal outcome associated with meconium- stained liquor in our institution.

\section{METHODS:}

The present prospective study was conducted in North Bengal Medical College, Sirajganj, a peripheral tertiary care center, between January 2016 - April 2017. Singleton pregnant women who exhibited meconium-stained liquor (MSL) on spontaneous or artificial rupture of membrane after 37 completed weeks of gestation with cephalic presentation of fetus formed the study subjects. However, pregnant women with previous cesarean sections, malpresentations of fetus (like breech or transverse lie) were excluded. Based on these enrollment criteria, a total of 53 pregnant women on labor were consecutively included in the study. Meconium-stained liquor was graded as "Thick" if the fluid was dark/deep green in colour, viscous, tenacious, opalescent or opaque and contained large amount of particulate materials and "Thin" if the fluid was translucent, light yellow in colour without particulate material.

Intrapartum cardiotocographic tracing was also taken for assessing fetal hypoxia during labor. Bradycardia was considered when fetal heart rate was $<110 \mathrm{bpm}$ and tachycardia when fetal heart rate was $>160 \mathrm{bpm}$. Delivery was expedited when fetal heart rate abnormalities were detected by the safest mode of delivery either by instrumental vaginal delivery or caesarean section. All patients underwent full trial of labor and caesarean section was done only if trial of labor was unsuccessful or if there were obstetric indications including fetal distress. The APGAR score of neonates, NICU admission, resuscitation needed, jaundice, respiratory distress syndrome (RDS) due to meconium aspiration were recorded. Asphyxia neonatorum was diagnosed if APGAR at birth and at 5 minutes was $<7$. 
Neonates were considered non-asphyxiated and in good condition when Apgar score was 7 or more while they were considered moderately asphyxiated when the score was between 4 to 6 and grossly asphyxiated when score was below 4 . Resuscitation was considered according to need, determined by Apgar scoring and in consultation with a neonatologist. Neonates with Apgar 5-6 were placed with the mothers and neonates with Apgar $<5$ were transferred to NICU for observation. If they developed any sign of complications within 24 hours were kept in NICU. Data were analyzed using SPSS (Statistical Package for Social Sciences), version 25.0. The test statistics used to analyze the data were descriptive statistics and Chi-squared Test. The predictors of neonatal outcome were determined using Chi-squared $\left(\chi^{2}\right)$ Test and the risk of having odd outcome was determined by Odds Ratio (OR) with its $95 \%$ confidence interval. The level of significance was set $5 \%$ and $p$-value $<0.05$ was considered significant.

\section{RESULT:}

\section{Demographic and obstetric characteristics:}

Maternal age distribution shows that two-thirds (67.9\%) of the mothers were $20-30$ years old and $28.3 \% 30-40$ years old with median age of the mothers being 25 years. Over half (56.6\%) of the subjects was multipara. Over one-quarter (28.3\%) received regular antenatal care (ANC), $43.4 \%$ irregular ANC and the rest (28.3\%) did not receive any care. Approximately $70 \%$ were at term (37-39 weeks) pregnancy and 30\% were full-term pregnant. Nearly half (47.2\%) attended the present hospital with their own initiative and the rest were referred by their relatives, doctors, nurses/midwifes (Table I).

\section{Presence of high-risk conditions or factors:}

Over $45 \%$ of the mothers presented with cord prolapse followed by oligohydramnios (32.1\%), preeclampsia (15.1\%), prolonged labor (11.3\%), PROM (11.3\%) and gestational diabetes mellitus $(9.4 \%)$. The minor problems were gestational hypertension, IUGR and UTI (Table II). More than one-quarter $(26.4 \%)$ of the fetus had normal heart rate, $28.3 \%$ bradycardia and $45.3 \%$ tachycardia. Over half (50.9\%) had yellowish liquor amni (grade-I), 34\% green liquor (grade-II) and $15.1 \%$ thick deep-green, tenacious liquor (grade-III) (Table III).

\section{Outcome:}

Majority $(84.9 \%)$ of the neonates was delivered by lower uterine caesarean section (LUCS) and approximately $80 \%$ were asphyxiated at 1 minute of birth which reduced to $15.1 \%$ at 5 minutes. More than three-quarters $(75.5 \%)$ of the neonates required resuscitation. However, only $1(1.9 \%)$ neonate needed ICU admission (Table IV). The commonest neonatal complication encountered by the neonates was respiratory distress syndrome (28.3\%), followed by neonatal jaundice $(9.4 \%)$, meconium aspiration syndrome $(7.5 \%)$ \& neonatal sepsis $(3.8 \%)$. Only $1(1.9 \%)$ neonate died of the complication (Table V).

\section{Association between grade of meconium during labor and perinatal outcome:}

Analyses of association between grade of meconium and perinatal outcome revealed that incidence of asphyxiated neonates (APGAR1 < 7) was significantly higher in thick meconium cohort than that in thin meconium cohort $(p=0.021)$. The risk of having asphyxia neonatorum in thick meconium cohort was 6 -fold ( $95 \% \mathrm{CI}=1.1-31.2$ ) higher than that thin meconium cohort. A substantial proportion of $(88.5 \%)$ of the neonates born of mothers with thick meconium during labor needed resuscitation compared to $63 \%$ of neonates born of mothers with thin meconium ( $p$ $=0.031$ ) with odds of needing resuscitation in the former cohort was $4.5(95 \% \mathrm{CI}=1.1-18.9)$ times higher. The incidence of respiratory distress syndrome (RDS) was also significantly higher in neonates born of mothers with thick meconium with risk of developing RDS in the former cohort was more than $4(95 \%$ CI $=1.1-15.7)$ times higher $(p=0.026)$ (Table VI). 


\begin{tabular}{|c|c|c|c|}
\hline $\begin{array}{l}\text { Obstetric } \\
\text { characteristics }\end{array}$ & Frequency & Percentage & $\begin{array}{c}\text { Mean } \pm S D \\
\text { (range) }\end{array}$ \\
\hline \multicolumn{4}{|l|}{ Age (years)* } \\
\hline$<20$ & 01 & 1.9 & \\
\hline $20-30$ & 36 & 67.9 & $25.0 \pm 5.3(18-43)$ \\
\hline $30-40$ & 15 & 28.3 & \\
\hline$\geq 40$ & 01 & 1.9 & \\
\hline \multicolumn{4}{|l|}{ Parity } \\
\hline Primi & 23 & 43.4 & -- \\
\hline Multi & 30 & 56.6 & -- \\
\hline \multicolumn{4}{|l|}{ Gestational age (weeks) } \\
\hline 37-39 weeks (Term) & 37 & 69.8 & -- \\
\hline 40-42 weeks (Full-term) & n) 16 & 30.2 & -- \\
\hline \multicolumn{4}{|l|}{ ANC received } \\
\hline Regular & 15 & 28.3 & -- \\
\hline Irregular & 23 & 43.4 & -- \\
\hline None & 15 & 28.3 & -- \\
\hline \multicolumn{4}{|l|}{ Referred by } \\
\hline Relative & 8 & 15.1 & -- \\
\hline Midwife & 4 & 7.5 & -- \\
\hline Doctor & 6 & 11.3 & -- \\
\hline Nurse & 10 & 18.9 & -- \\
\hline Self & 25 & 47.2 & -- \\
\hline
\end{tabular}

Table II. Distribution of patients by presence of associated risk factors $(n=53)$

$\begin{array}{lcc}\begin{array}{l}\text { Presence of } \\ \text { associated risk factors }\end{array} & \text { Frequency } & \text { Percentage } \\ \text { Cord around neck } & 24 & 45.3 \\ \text { Oligohydramnios } & 17 & 32.1 \\ \text { Preeclampsia } & 8 & 15.1 \\ \text { Prolonged labour } & 6 & 11.3 \\ \text { PROM } & 6 & 11.3 \\ \text { Gestational DM } & 5 & 9.4 \\ \text { Gestational HTN } & 2 & 3.8 \\ \text { IUGR } & 1 & 1.9 \\ \text { UTI } & 1 & 1.9 \\ \text { Others } & 16 & 30.2\end{array}$

\begin{tabular}{|c|c|c|}
\hline Examination findings & Erequency & Percentage \\
\hline \multicolumn{3}{|l|}{ Foetal heart during perinatal period } \\
\hline Normal & 14 & 26.4 \\
\hline Bradycardia & 15 & 28.3 \\
\hline Tachycardia & 24 & 45.3 \\
\hline \multicolumn{3}{|l|}{ Amount of liquor amni (by USG) } \\
\hline Adequate & 15 & 28.3 \\
\hline Inadequate & 22 & 41.5 \\
\hline Scanty & 16 & 30.2 \\
\hline \multicolumn{3}{|l|}{ Meconium staining liquor } \\
\hline Light yellow or light green (G-I) & 27 & 50.9 \\
\hline Green (G-II) & 18 & 34.0 \\
\hline Dark green, tenacious and opaque (G-III & III) 8 & 15.1 \\
\hline
\end{tabular}

Table IV. Distribution of patients by their outcome $(n=53)$

\begin{tabular}{|c|c|c|c|}
\hline $\begin{array}{l}\text { Obstetric } \\
\text { characteristics }\end{array}$ & Frequency & Percentage & $\begin{array}{l}\text { Mean } \pm \text { SD } \\
\quad \text { (range) }\end{array}$ \\
\hline \multicolumn{4}{|l|}{ Mode of delivery } \\
\hline SVD & 8 & 15.1 & -- \\
\hline LUCS & 45 & 84.9 & -- \\
\hline \multicolumn{4}{|l|}{ APGER 1} \\
\hline$<7$ & 42 & 79.2 & -- \\
\hline$\geq 7$ & 11 & 20.8 & -- \\
\hline \multicolumn{4}{|l|}{ APGER 5} \\
\hline$<7$ & 8 & 15.1 & -- \\
\hline$\geq 7$ & 45 & 84.9 & -- \\
\hline Resuscitation needed & 40 & 75.5 & -- \\
\hline Admission in ICU & 1 & 1.9 & -- \\
\hline Birth weight (kg) & -- & -- & $2.9 \pm 0.4(1.9-3.9)$ \\
\hline
\end{tabular}

Table V. Distribution of patients by their neonatal complication $(n=53)$

$\begin{array}{lcc}\text { Neonatal complication } & \text { Frequency } & \text { Percentage } \\ \text { Meconium Aspiration syndrome } & 4 & 7.5 \\ \text { Respiratory distress syndrome } & 15 & 28.3 \\ \text { Neonatal jaundice } & 5 & 9.4 \\ \text { Neonatal sepsis } & 2 & 3.8 \\ \text { Perinatal death } & 1 & 1.9\end{array}$




\begin{tabular}{|c|c|c|c|c|}
\hline \multirow{2}{*}{$\begin{array}{l}\text { Perinatal } \\
\text { outcome }\end{array}$} & \multicolumn{2}{|c|}{ Grade of Meconium } & \multirow{2}{*}{$\mathrm{p}$-value } & \multirow{2}{*}{$\begin{array}{l}\text { Odds Ratio } \\
\text { (95\% Cl of OR) }\end{array}$} \\
\hline & $\begin{array}{l}\text { Thick } \\
(n=26)\end{array}$ & $\begin{array}{l}\text { Thin } \\
(n=27)\end{array}$ & & \\
\hline \multicolumn{5}{|c|}{ Mode of delivery* } \\
\hline NVD & $3(11.5)$ & $5(18.5)$ & \multirow{2}{*}{0.374} & \multirow{2}{*}{ NC\# } \\
\hline LUCS & $23(88.5)$ & $22(81.5)$ & & \\
\hline \multicolumn{5}{|c|}{ APGAR score at birth** } \\
\hline$<7$ & $24(92.3)$ & $18(66.7)$ & \multirow{2}{*}{0.021} & \multirow{2}{*}{$6(1.1-31.2)$} \\
\hline$\geq 7$ & $2(7.7)$ & $9(33.3)$ & & \\
\hline \multicolumn{5}{|c|}{ APGAR score at $5 \mathrm{~min}$. } \\
\hline$<7$ & $6(23.1)$ & $2(7.4)$ & \multirow{2}{*}{0.113} & \multirow{2}{*}{$N C^{\#}$} \\
\hline$\geq 7$ & $20(76.9)$ & $25(92.6)$ & & \\
\hline \multicolumn{5}{|c|}{ Resuscitation needed ${ }^{* *}$} \\
\hline Yes & $23(88.5)$ & $17(63.0)$ & \multirow{2}{*}{0.031} & \multirow{2}{*}{$4.5(1.1-18.9)$} \\
\hline No & $3(11.5)$ & $10(37.0)$ & & \\
\hline \multicolumn{5}{|c|}{ ICU admission needed* } \\
\hline Yes & $1(3.8)$ & $0(0.0)$ & \multirow{2}{*}{0.491} & \multirow{2}{*}{ NC\# } \\
\hline No & $25(96.2)$ & $27(100.0)$ & & \\
\hline \multicolumn{5}{|l|}{ RDS** } \\
\hline Yes & $11(42.3)$ & $4(14.8)$ & \multirow[t]{2}{*}{0.026} & \multirow[t]{2}{*}{$4.2(1.1-15.7)$} \\
\hline No & $15(57.7)$ & $23(85.2)$ & & \\
\hline \multicolumn{5}{|l|}{ Jaundice* } \\
\hline Yes & $3(11.5)$ & $2(7.4)$ & \multirow{2}{*}{0.482} & \multirow{2}{*}{$N C^{\#}$} \\
\hline No & $23(88.5)$ & $25(92.6)$ & & \\
\hline \multicolumn{5}{|l|}{ Sepsis* } \\
\hline Yes & $1(3.8)$ & $1(3.7)$ & \multirow{2}{*}{0.745} & \multirow{2}{*}{$N C^{\#}$} \\
\hline No & $25(96.2)$ & $26(96.3)$ & & \\
\hline \multicolumn{5}{|l|}{ Mortality* } \\
\hline Yes & $1(3.8)$ & $(0.0)$ & \multirow{2}{*}{0.491} & \multirow{2}{*}{$N C^{\#}$} \\
\hline No & $25(96.2)$ & $27(100.0)$ & & \\
\hline
\end{tabular}

Figures in the parentheses indicate column-wise $\%$.

*Fisher's Exact Test was done to analyze the data; ${ }^{*} \chi^{2}$ Test was done to analyze the data. \# if two Categorical variables are not associated, Odds Ratio need not to be Computed (NC)

\section{DISCUSSION:}

The significance of meconium in amniotic fluid is a widely debated subject. Passage of meconium may be a normal physiological event reflecting fetal maturity. It also reflects fetal hypoxia or increased vagal activity from cord compression. The presence of meconium during labor is associated with an increased risk of perinatal mortality and morbidity. The present study intended to determine the association between
MSAF and its fetal outcome in parturients found that asphyxia neonatorum (APGAR $1<7$ ), need for resuscitation and RDS were significantly higher in 'Thick' meconium cohort than that in 'Thin' meconium cohort with risks of having these conditions in the former cohort being $6(95 \% \mathrm{CI}=$ $1.1-31.2), 4.5(95 \%$ CI $=1.1-18.9)$ and $4.2(95 \%=1.1-15.7)$ times higher respectively than those in the latter cohort. The major complication associated with MSAF was birth asphyxia. Most investigators showed there is an association of fetal heart rate abnormalities with low Apgar scores and low arterial cord blood $\mathrm{pH}$ in the presence of meconium stained amniotic fluid. ${ }^{12}$ Samiyappa and associates ${ }^{13}$ in a similar study in India demonstrated that thick meconium was associated with low Apgar score, increased incidence for NICU admission and meconium aspiration syndrome and required prompt intervention. Incidence of fetal heart rate abnormalities was higher in thick meconium accounting for increased incidence of operative deliveries and low Apgar Score. ${ }^{14}$ Vaghela et a ${ }^{15}$ showed APGAR score in first minute to be low $(<7)$ in $5.2 \%$ of neonates with thin meconium as compared to $18.5 \%$ of neonates with thick meconium. Sedaghatian and associates ${ }^{16}$ found similar result in their study. Patil et al. ${ }^{17}$ observed much higher incidence $(26.2 \%)$ of low $(<7)$ APGAR score in patients with thick meconium than that in patients with thin meconium $(6.7 \%)$

Type of MSAF certainly influences the mode of delivery. Several investigators have shown higher rates of LUCS and instrumental vaginal deliveries in thick meconium group as compared to thin meconium group. ${ }^{18,19}$ In the present study, the incidence of caesarean delivery although was a bit higher in the 'Thick' meconium Group than that in the 'Thin' meconium group, the difference did not turn significant. In spite of that the present study had higher rates of LUCS, because obstetricians were more concerned in labors with MSAF as our center does not have facilities for continuous FHR monitoring and facilities for fetal scalp blood 
sampling. Thus, in the absence of these facilities there is an increase in instrumental vaginal deliveries and caesarean section rate.

Presence of meconium in the amniotic fluid during labor often causes anxiety in delivery room, for it is implicated as a fetal and neonatal wellbeing during the intrapartum and postpartum periods respectively. However, MSAF in cephalic presentation is of greater concern even to senior and experienced obstetricians and midwives. Whereas detection of meconium in breech presentation is not much of concern as it is due to mechanical compression of fetal abdomen. Fetal status during labor is usually assessed by measuring the fetal heart rate abnormalities and checking the colour of the amniotic fluid. It is often assumed that fetal heart rate abnormalities, especially in the presence of meconium stained liquor indicates hypoxia and acidosis. ${ }^{20}$

Although 70\% of newborns pass meconium by 12 hours of age, many infants pass meconium prior to birth as well. ${ }^{21}$ It has been suggested that the fetus passes meconium in response to hypoxia signaling fetal compromise. Alternatively, in utero passage of meconium may represent normal gastrointestinal tract maturation under neuronal control. Meconium passage could also follow vagal stimulation from transient umbilical cord entrapment. ${ }^{22}$ Traditionally meconium has been viewed as a harbinger of impending or ongoing fetal compromise; however, some investigators believe that it is not associated with fetal hypoxia, acidosis or feta distress. The predictive value of meconium is better when it occurs in high risk patients and is thick, dark and tenacious. Lightly stained meconium has a poor association with feta hypoxia. ${ }^{23}$ Summarizing the findings of the study and those of others compared and contrasted suggests following conclusions:

\section{CONCLUSION:}

Of the meconium-stained liquor, nearly half is with thick meconium which generally carries unfavourable perinatal outcome. Majority of the thick meconium cases encounter asphyxia neonatorum, need resuscitation and develop RDS. Asphyxia neonatorum, need for resuscitation and RDS are significantly higher in 'Thick' meconium cohort than those in 'Thin' meconium cohort with risks of having these conditions in the former cohort being several times higher than those in the latter cohort. The occurrence of MSAF during labor is associated with increased caesarean section as well.

\section{REFERENCES:}

1. Oyelese $Y$, Culin A, Ananth CV, Kaminsky LM, Vintzileos A, Smulian JC, et al. Meconium stained amniotic fluid across gestation and neonatal acid base status. Obstet Gynecol 2006;108:345.

2. Wong SF, Chow KM, Ho LC. The relative risk of foetal distress in pregnancy associated with meconium stained liquor at different gestations. AMJ Obstet Gynaecol 2002;22:594-9.

3. Ashfaq F, Shah AA, Effect of amnioinfusion for meconium stained amniotic fluid on perinatal outcome. J Pak Med Assoc 2004; 54:322-5.

4. Yamada T, Minakami H, Matsubara S, Yatsuda T. Meconium stained amniotic fluid exhibits chemotactic activity for polymorphonuclear leukocytes in vitro. J Reprod Immunol 2000;46:2130.

5. Low JA, Pancham SR, Worthington O, Bolton RW. The incidense of fetal asphyxia in 600 high risk monitored pregnancies. Am J Obstet Gynecol 1975;121:456- 59.55.

6. Meis $\mathrm{PJ}$, Hall M, Marshall JR, Hobel CJ. Meconium passage: a new classification for risk assessment during labour. Am J Obstet Gynecol 1978;131:509-13.

7. Abramovici H, Brandes JM,Fuchs K, Timor FI.Meconium during delivery, a sign of compensated fetal distress. Am J Obstet Gynecol 1974;118:251-55.

8. Shaikh EM, Mehmood S, Shaikh MA. Neonatal outcome in meconium stained amniotic fluid-one year experience. J Pak Med Assoc 2010;60:711-4.

9. Paul J, Hall M, Marshall JR, Hobel CJ. Meconiumpassage: a new. 1978;31:509-13.

10. Steer PJ, Daniethian P. Foetal distress in labour. In: James DK, Steer PJ, Weiner CP, Gonaik B editors. High risk pregnancy: management options. $3^{\text {rd }}$ edition. Philadelpia: Elsevier Inc 2006:1450-72.

11. Goud P, Krishna U. Significance of meconium staining of amniotic fluid in labour. $J$ Obstet and Gynaecol India 1989;39:523-6. 
12. Oyelese $Y$, Culin A, Ananth CV, Kaminsky LM, Vintzileos A, Smulian JC, et al. Meconium stained amniotic fluid across gestation and neonatal acid base status. Obstet Gynecol 2006;108:345.

13. Samiyappa DP, Ghose S, John LB, Samal R. Maternal and perinatal outcome in meconium stained amniotic fluid at term: a case control study. International Journal of Reproduction, Contraception, Obstetrics \& Gynecology Samiyappa DP et al. Int J Reprod Contracept Obstet Gynecol 2016;5(10):3404-3410DOI:http://dx.doi.org/10. 18203/2320-1770.ijrcog 20163413

14. Singh $P$ and Soren SN. A study of perinatal outcome in meconium stained amniotic fluid. Med Pulse International Medical Journal 2017;4(1):06-13.

15. Vaghela HP, Deliwala K, Shah P. Fetal outcome in deliveries with meconium stained liquor. Int J Reprod Contracept Obstet Gynecol 2014;3(4):909-912 http:// dx.doi.org/10.5455/2320-1770.ijrcog2014120.

16. Sedaghatian MR, Otheman L, Rashid N,Ramachandran $\mathrm{P}$, Bener BA. An 8 year study ofmeconium stained amniotic fluid in differentethnic groups. Kuwait Medical Journal 2004;36:266-69.

17. Patil KP, Swamy MK, Samatha K. A one yearcross sectional study of management practicesof meconium stained amniotic fluid and perinatal outcome. Obstet Gynecol India 2006;56:128-30.
18. Supriya K, Suchitra T, Prakhar S. Clinical study of meconium stained amniotic fluid. International Journal of Biomedical \& Advance Research 2014;05 (12):612-614.

19. Shazia Q, Jan S, Chachoo JA. Perinatal and neonatal outcome in meconium stained amniotic fluid. International Journal of Reproduction, Contraception, Obstetrics and Gynecology 2016;5(5):1400-1405.DOI:http://dx.doi.org/ 10.18203/2320-1770.ijrcog 20161293

20. Perinatology and contraception-Dutta DC. In: Konar $\mathrm{H}$ editor. Textbook of Obstetrics .6th ed. calcutta: New Central Book Agency (p) Ltd; 2004:256.

21. Wood CL. Meconium stained amniotic fluid Nurse Midwifery. J Nurse Midwifery 1994;39(2Suppl): 106S109S.

22. Cunningham AS, Lawson EE, Martin RJ, Pildes RS. Tracheal suction and meconium:a proposed standard of care. J pediatr 1990;116(1):153-44.

23. Ratnam SS, Rao BK, Arulkumaran S. Practical approach to Intrapartum fetal monitoring in labour. Chapter 12. Obstetricsand Gynecology for Postgraduates 1992;1: 115-251. 